\title{
Reducing Perioperative Risks of Surgery in Crohn's Disease
}

\author{
Wolfgang Reindl ${ }^{a} \quad$ Anne Kerstin Thomann $^{a} \quad$ Christian Galata $^{b} \quad$ Peter Kienle $^{c}$ \\ all Medizinische Klinik, Universitätsmedizin Mannheim, Medizinische Fakultät Mannheim, Universität \\ Heidelberg, Mannheim, Germany; ${ }^{b}$ Chirurgische Klinik, Universitätsmedizin Mannheim, Medizinische Fakultät \\ Mannheim, Universität Heidelberg, Mannheim, Germany; ${ }^{\mathrm{C}}$ Abteilung für Allgemein- und Viszeralchirurgie, \\ Theresienkrankenhaus und St. Hedwig-Klinik GmbH Mannheim, Mannheim, Germany
}

\section{Keywords}

Inflammatory bowel disease · Crohn's disease .

Immunosuppressive therapy · Surgery · Complications .

Perioperative planning

\section{Abstract}

Background: Approximately one-third of all patients suffering from Crohn's disease (CD) undergo surgery within the first 10 years after diagnosis and another $20 \%$ will have a second operation in the 10 years after their first operation. Surgery will remain an essential part of managing $C D$ and therefore it is crucial to prevent perioperative complications by optimizing perioperative management. Methods: We reviewed the current literature on managing immunomodulating therapy, nutritional support, and thromboembolic prophylaxis in the perioperative situation. Results: CD patients with serious nutritional deficits (weight loss $>10 \%$ in the last 3-6 months, body mass index $<18.5 \mathrm{~kg} / \mathrm{m}^{2}$, or albumin levels $<30 \mathrm{~g} / \mathrm{L}$ ) benefit from intensive enteral or parenteral nutritional support, thereby reducing the risk of surgical-site infections and post-operative septic complications. Immunosuppressive therapy with prednisolone doses $>20$ mg should be avoided. The risk of therapy with anti-TNFa agents, vedolizumab, and ustekinumab for surgical complications has not been fully established. Analysis of currently available data suggests that an interval of 4-8 weeks is prudent to avoid complications and reduce risk by performing protective ostomy in the emergency setting. Finally, due to the high risk of venous thromboembolism, prophylactic therapy with heparin is recommended. Conclusion: As most cases of CD-related surgery are performed in a non-emer- gency setting, careful planning and risk management can reduce the rate of surgical complications, increase quality of life, and also reduce costs.

c 2019 S. Karger AG, Basel

\section{Introduction}

Surgery for intestinal resection remains an essential step in the care of patients with Crohn's disease (CD). Recent studies show a strong trend for a longer time to first resection and an overall reduction in the proportion of patients in need of surgery during the first 10 years of the disease [1]. This trend can probably be attributed to the increasing number of immunomodulatory therapies [2], but definitive proof is still lacking. Interestingly, the rate of emergency resection has declined steeply while the number of planned resections shows a slight increase [3]. This trend might result from a change in treatment strategy, i.e., moving away from reacting when disease activity flares to constant monitoring of disease progression. Nevertheless, $21 \%$ of our patients will undergo surgery within 10 years from disease onset and $17-33 \%$ will have a second resection in the 10 -year period following the first resection [4]. Recent data also show that in patients with limited disease in the ileo-coecum who fail on first-line therapy, resection could be a favourable therapeutic option that provides a better quality of life and at lower costs than infliximab treatment [5]. This outcome was only

Christian Galata and Peter Kienle contributed equally to this work.

\section{KARGER}

(c) 2019 S. Karger AG, Basel 
Fig. 1. Preoperative management of IBD patients. EEN, exclusive enteral nutrition; IBD, inflammatory bowel disease; ONS, oral nutritional supplements; TPN, total parenteral nutrition.

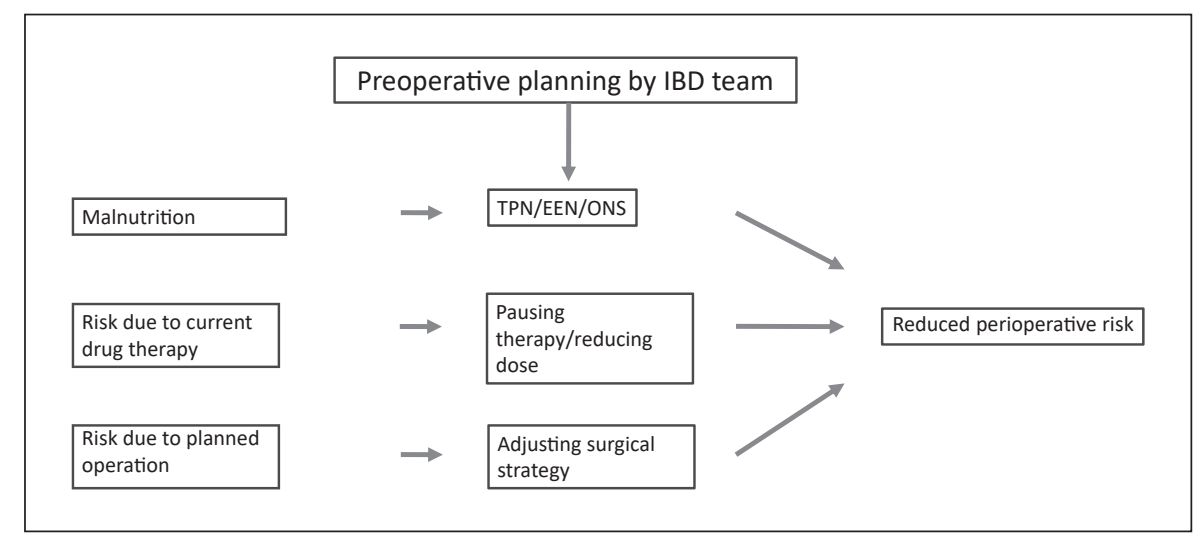

possible due to a very low rate of surgical complications. This article highlighted the importance of perioperative management for CD patients, preferentially in a multidisciplinary team, to achieve a favourable outcome. This review focuses on the strategies to prevent surgical complications in patients with CD undergoing bowel resection and discusses current strategies for preventing an early post-operative recurrence of CD.

Complications in CD patients admitted for surgery are partially attributable to immobilization, the severity of the underlying disease as well as septic complications in patients treated with immunosuppression. Furthermore, there are specific surgical problems caused by anastomotic leaks or soft-tissue infections. While the latter undoubtedly lead to a reduced quality of life and increased costs, the former determine mortality and the long-term success of the procedure. Studies on factors modifying the short-term outcome of surgical procedures in CD patients are mostly non-randomised, small, retrospective and with conflicting outcomes. In analysing the results of recent, larger trials, certain parameters come into focus: nutritional deficits, immunosuppressive therapy, thromboembolic events, and a possible benefit of high-volume surgical centers. Careful planning reduces the risk for the CD patient undergoing surgery (Fig. 1).

\section{Prophylaxis against Thromboembolism}

Large studies show that patients with inflammatory bowel disease (IBD) have an increased risk of developing venous thromboembolism and pulmonary embolism (RR 1.96 [95\% CI 1.67-2.30] and 2.42 [1.78-3.30], respectively) [6]. More recent data have shown an increase in thromboembolic events in hospitalized patients with IBD [7]. Data from the American College of Surgeons National Quality Improvement Program showed a rate of $1.4 \%$ of thromboembolic events (deep vein thrombosis or pulmonary embolism) for patients undergoing surgery for $\mathrm{CD}$, and a rate of $3.3 \%$ in patients with ulcerative colitis
(UC) [8]. Further analysis identified bleeding disorders, emergency surgery, anaemia, steroid use, and malnutrition as risk factors for thromboembolic events. Chu et al. [9] reported an increased risk for up to 6 weeks after discharge. Brady et al. [10] suggested that certain operations (stoma [OR 1.95] and J-pouch [OR 2.66] creation) and preoperative conditions like prednisone use (OR 1.57) entail an increased risk and therefore justify anti-thrombotic prophylaxis post-discharge. The European Crohn's and Colitis Organization (ECCO) [11] published guidelines recommend prophylaxis with unfractionated or low-molecular-weight heparin for IBD patients undergoing surgery. In addition to drug-based prophylaxis, patients should wear compression stockings and undergo early mobilization as part of the enhanced recovery after surgery (ERAS) process [12].

\section{Nutrition Influencing Post-Operative Outcome}

While there is evidence from randomised trials and meta-analyses for the beneficial effect of prehabilitation in colorectal surgery [13] and large randomised trials are recruiting patients with colorectal cancer [14], data on CD patients are still very limited. Only $14 \%$ of patients undergo emergency surgery, $72 \%$ of all operations are elective, and the remaining ones are performed with up to 2 weeks of advance planning.

Studies investigating nutritional support have compared different methods, e.g., parenteral supplementation, total parenteral nutrition (TPN), and exclusive enteral nutrition (EEN), with a variety of formulations. In a recent systematic review, Grass et al. [15] identified 14 studies providing evidence of a reasonable quality. Of these, only 3 showed no improvement when nutritional support was provided. Interestingly, EEN and TPN resulted in a significant decrease in inflammatory burden, specific infectious complications, and non-infectious complications. In a recent retrospective study, Ayoub et al. [16] showed that even in patients with severe malnutri- 
tion (defined as serum albumin $<30 \mathrm{~g} / \mathrm{L}$, weight loss $>10 \%$ in the last 6 months, or a BMI $<18.5 \mathrm{~kg} / \mathrm{m}^{2}$ ) and severe $\mathrm{CD}$, preconditioning by intensive TPN resulted in a rate of post-operative complications equal to a control group (matched for disease behaviour, surgical intervention, and preoperative medical therapy) without malnutrition.

Interestingly, parenteral nutrition for $>60$ days resulted in a significantly lower risk of developing post-surgical non-infectious complications 30 days after surgery. While TPN for $>60$ days is associated with high costs and demands specialized support, EEN offers an interesting alternative, but there is currently no published or registered head-to-head trial that compares these 2 approaches. Interestingly, most successful interventions apply nutritional support (EEN or TPN) for $\geq 4$ weeks prior to planned surgery [17-20]. This finding is consistent with the proven efficacy of EEN as a treatment for paediatric $\mathrm{CD}$ [21]. The mechanisms of EEN are yet not fully understood, but the data show a relevant change in intestinal microbiota with consecutive changes in intestinal immune responses [22].

Importantly, enteral nutritional supplementation alone does not result in this response. Recent data in a small clinical trial provided evidence that a personalized, food-based diet may provide similar results while being more tolerable for the patients [23]. The current ESPEN guidelines on clinical nutrition in surgery [24] do not offer specific advice for the treatment of IBD patients, but they do provide guidance for patients with nutritional deficits based on best current evidence. Patients suffering from conditions that reduce the ability to absorb enteral nutrition should be provided with parenteral nutrition [25]. While this approach results in a correction of the underlying nutritional deficit, it fails to address the inflammatory response due to immune activation, so EEN might offer an additional benefit, but this hypothesis has yet to be validated in prospective trials.

All CD patients scheduled for surgery should be screened for signs of malnutrition by using an established screening tool like the nutritional risk score (NRS). When the NRS is positive, high-risk patients should be identified (albumin $<30 \mathrm{~g} / \mathrm{L}$, weight loss $>10-15 \%$ within 6 months, or a BMI $<18.5$ ) and the decision to initiate TPN or EEN should be discussed with a specialist, while malnourished patients considered to not be at a high risk should receive oral nutritional supplements [15].

\section{Preoperative Immunomodulating Therapy}

As most patients are under treatment when surgery is scheduled, the decision as to whether the current therapy should be continued or halted must be discussed for every individual case. Stopping it might result in a rapid dete- rioration of the patient's condition and also increase the risk of secondary failure when therapy is restarted after surgery. On the other hand, continued therapy might increase the risk for complications during surgery. The available data are mostly derived from retrospective studies. The criteria for initiating drugs vary widely, especially with regard to biological therapies. Such differences lead to differences in outcome. The most recent analysis evaluating a very large cohort of 3,860 patients undergoing colonic resection confirmed the finding that steroids and other immunosuppressant medication within 30 days of planned surgery can increase the odds for infectious complications (OR 1.25 [95\% CI 1.033-1.523]) or surgical-site infections and anastomotic leak (OR 1.51 [95\% CI 1.018-2.250]) [26]. The increased risk for perioperative complications in patients treated with steroids has already been established, e.g., Nguyen et al. [27] identified an increased risk of post-operative complications, thromboembolism, and mortality in steroid-treated patients. In accordance with the current ECCO-ESCP guidelines, we recommend reducing the daily steroid dose to $<20 \mathrm{mg}$ prednisolone [28]. There is currently no evidence to support a higher steroid dose as compensation for a potentially reduced adrenal function due to higher preoperative doses of steroids.

Due to a lack of large prospective trials, the preoperative management of patients treated with TNF- $\alpha$ inhibitors (TNFi) is still a matter of debate. To reduce the bias of drug exposure we only evaluated studies involving exposure to TNFi up to 8 weeks before surgery. As the halflife of infliximab and adalimumab is $8-10$ and $10-14$ days, respectively [29], a longer interval between exposure and surgery makes a direct drug-induced effect unlikely. Furthermore, we excluded single-centre studies. Using these criteria, we found 6 studies (Table 1).

This analysis focuses on the more recent studies and highlights an interesting finding. While the retrospective studies found no increase in complications after the use of TNFi, all prospective trials found an increase of postoperative complications after the use of TNFi. This was surprising, especially since in the cohort analysed by Abou Khalil et al. [26], significantly more patients in the non-immunosuppressed cohort were suffering from diabetes ( 4.28 vs. $3.06 \% ; p=0.047)$ and the mean age in this group was significantly higher (43.5 vs. 38.96 years; $p<$ 0.001). In line with these findings, Lau et al. [35] found a significant increase in post-operative morbidity (OR 2.5; $p=0.03$ ) and infectious complications (OR 3.0; $p=0.03$ ) in the group of $\mathrm{CD}$ patients with preoperative drug levels $>3 \mu \mathrm{g} / \mathrm{mL}$, and a further increase in complications with drug levels $>8 \mu \mathrm{g} / \mathrm{mL}$. In the UC group, the authors found no relevant increase in complications for colectomies, but all of these procedures were performed as 3-stage procedures that omitted the need for primary anastomosis 
Table 1. Summary of studies involving preoperative management with TNF- $\alpha$ inhibitors (TNFi)

\begin{tabular}{|c|c|c|}
\hline $\begin{array}{l}\text { Reference } \\
\text { (study type) }\end{array}$ & $\begin{array}{l}\text { Subjects, } n \\
\text { (patients vs. controls) }\end{array}$ & Summary of outcome \\
\hline $\begin{array}{l}\text { Myrelid et al. } \\
{[30], 2014} \\
\text { (retrospective, } \\
\text { multi-centre) }\end{array}$ & 298 (111 vs. 187) & $\begin{array}{l}\text { Equal rate of complications in total ( } 34 \text { vs. } 29 \% \text { ); } \\
\text { specifically, no difference in rate of anastomotic } \\
\text { complications ( } 7 \text { vs. } 8 \% \text { ) and infections ( } 16 \text { vs. } 14 \% \text { ) }\end{array}$ \\
\hline $\begin{array}{l}\text { Yamamoto et al. } \\
\text { [31], } 2016 \\
\text { (retrospective, } \\
\text { multi-centre) }\end{array}$ & 231 (79 vs. 152) & $\begin{array}{l}\text { No increase in overall post-operative complications, } \\
\text { intra-abdominal sepsis or anastomotic leak after TNFi } \\
\text { therapy }\end{array}$ \\
\hline $\begin{array}{l}\text { Kotze et al. } \\
{[32], 2017} \\
\text { (retrospective, } \\
\text { multi-centre) }\end{array}$ & 123 (71 vs. 52 ) & $\begin{array}{l}\text { Equal proportion of surgical complications ( } 39 \text { vs. } 33 \%) \\
\text { and overall medical complications ( } 21 \text { vs. } 22 \%)\end{array}$ \\
\hline $\begin{array}{l}\text { Brouquet et al. } \\
\text { [33], } 2018 \\
\text { (prospective, } \\
\text { nation-wide } \\
\text { cohort) }\end{array}$ & 592 (143 vs. 449$)$ & $\begin{array}{l}\text { TNFi therapy, haemoglobin }<10 \mathrm{~g} / \mathrm{dL} \text {, and operation } \\
\text { time }>180 \mathrm{~min} \text { identified as independent risk factors } \\
\text { for increased post-operative complications }\end{array}$ \\
\hline $\begin{array}{l}\text { Fumery et al. } \\
{[34], 2017} \\
\text { (prospective, } \\
\text { nation-wide } \\
\text { cohort) }\end{array}$ & 209 (93 vs. 116) & $\begin{array}{l}\text { Corticosteroid therapy inside } 4 \text { weeks prior to surgery } \\
\text { identified as the only independent risk factor for post- } \\
\text { operative complications (OR 2.69; 95\% CI 1.15-6.29) }\end{array}$ \\
\hline $\begin{array}{l}\text { Abou Khalil et al. } \\
{[26], 2019} \\
\text { (prospective, } \\
\text { nation-wide } \\
\text { cohort) }\end{array}$ & $3,860(2,483$ vs. 1,377$)$ & $\begin{array}{l}\text { Higher rates of complications } \\
\text { Infectious complications (OR } 1.25 ; 95 \% \text { CI } 1.033-1.523) \text {, } \\
\text { overall surgical-site infection }(1.40 ; 1.128-1.742) \text {, organ } \\
\text { space surgical-site infection }(1.47 ; 1.094-1.984) \text {, and } \\
\text { anastomotic leak ( } 1.51 ; 1.018-2.250) \text { in patients receiving } \\
\text { immunosuppression within } 30 \text { days of elective surgery }\end{array}$ \\
\hline
\end{tabular}

while the patients were being treated with immunomodulatory substances.

While there is an increasing number of well-designed studies for the use of TNFi, data on the more recently introduced vedolizumab (VDZ) and ustekinumab (UST) are limited. VDZ is approved for the treatment of CD and UC. Due to its mode of action of blocking the $\alpha 4-\beta 7$ integrin, a high specificity for the mucosal immune system is expected. This specificity is thought to be the reason for the favourable side effect profile seen in the phase 3 trials [36]. However, it would be inappropriate to expect that this gut specificity would guarantee a low risk during IBD-related surgery, especially considering the fact that local mucosal immune interaction is a crucial player in the local healing process.

Recent reviews of the current literature provide divergent results concerning the safety of VDZ in the perioperative setting for $\mathrm{CD}$. The meta-analysis by Yung et al. [37] did not find any differences in surgical-site infections, the overall infection rate, the need for repeated surgery, or major surgical complications in patients exposed to VDZ, TNFi, or no immunomodulation. In contrast, Lightner et al. [38] found a significant increase in the risk of surgical-site infections in the VDZ-treated patients compared to TNFi and non-immunomodulated controls in the multivariate analysis. Of note, they also failed to mention the study of Yamada et al. [39] in their assessment of VDZ-associated perioperative risk in CD patients; in this retrospective trial, $40 \mathrm{CD}$ patients were included and no difference in risk for perioperative complications was found. Including these data changed the overall results in Yung et al. [37]. Another meta-analysis by Law et al. [40] reported no increased risk of surgicalsite infections or overall surgical complications in patients treated with VDZ compared to patients treated preoperatively with TNFi or no biologics.

Finally, a recent prospective single-centre study [41] compared the outcome of patients treated with VDZ to case-matched controls treated with TNFi. In this mixed cohort (59 UC and 47 CD patients), univariate analysis found a significant increase in the risk for complications in all patients treated with biologics compared to patients 
not receiving this kind of therapy. In the multivariate analysis, however, only low haemoglobin, increased BMI, and longer surgery duration were identified as independent risk factors for infectious complications but neither TNFi nor VDZ therapy was associated with an increased risk. In keeping with their institutional policy, $80 \%$ of all patients received an ostomy, thereby reducing the risk significantly, compared to the ostomy rate of $11 \%$ in the VDZ group reported by Lightner et al. [38]. In summary, VDZ may be associated with an increased risk in patients receiving an anastomosis without protective ostomy while on full-dose VDZ preoperatively.

Only 2 studies, by Shim et al. [42] and Lightner et al. [43], have analysed the perioperative risk of UST for patients with $\mathrm{CD}$. Both were retrospective multi-centre studies that showed no increase in surgical-site infections or re-admissions in patients treated with UST compared to patients treated with TNFi. Of note, neither study compared the UST cohort to patients without biological therapy. Interestingly, in Shim et al. [42], 55\% of the patients in the UST cohort received an emergency procedure compared to only $25 \%$ in the TNFi control group. Despite the higher risk in this setting, post-operative infections were not more frequent. However, the ostomy rate in the UST group was 5.6 times higher than in the TNFi group (70 vs. $12.5 \%$ ).

\section{Experience and Risk of Complications}

It is acknowledged that, for specific interventions, there is a connection between the number of procedures performed and the outcome. Large-scale studies established this concept also for colorectal surgery [44]. In the treatment of CD patients, analysis of US hospital admission data showed a reduced mortality for patients undergoing surgery in high-volume centers, i.e., those managing $>150$ IBD-related admissions per year [45]. Interestingly, unlike with surgery for rectal carcinoma, there was only a weak association between outcome and the volume of IBD-related operations per individual surgeon [46]. The study by Nguyen et al. [27] showed a 1.5-fold increase only for the rate of late re-admission ( $>3$ months after surgery) when operated by a surgeon in the bottom quartile of surgery volume ( $<23$ [range 18-25] IBD-related operations/ year) compared to surgeons in all higher quartiles. These data indicate that it is probably more important for the overall outcome that the team has sufficient experience in treating IBD patients rather than relying on an individual's competence. However, a more specific assessment of certain specialized problems like surgical therapy of fistulas and rectal surgery could produce a different result concerning the experience of individual surgeons.

\section{Conclusion and Practical Approach}

Preoperative assessment of CD patients should involve a multi-disciplinary team experienced in the treatment of IBD patients. While data from trials to support this approach are lacking, outcome data support the idea that a more experienced team results in a better outcome for the patient. Every patient should be assessed for signs of malnutrition to receive the appropriate support if needed. Due to the still inconsistent data, we recommend halting immunosuppressive and immunomodulatory medication prior to elective surgery without planned ostomy, if possible. To this end, we recommend reducing the daily dose of prednisolone (equivalent) to $<20 \mathrm{mg}$. TNFi should not be administered within the 4 weeks before surgery, so as to provide an interval of nearly 3 halflives for most antibodies. Concerning VDZ and UST, the longer half-life would call for there to be 8 weeks between the last dose and the surgery. If continued medical treatment is necessary after surgery, at least 2 weeks should be allowed before biologics are administered to support normal wound-healing and reduce the risk of surgical-site infections.

In every case, the individual risk for each patient should be evaluated, taking into account their nutritional status, any co-existing medical conditions, and the estimated risk of the planned operation. For example, the risk of an isolated ileo-coecal resection is considerably lower than that of colonic resection [47]. If in doubt, or in cases of emergency surgery with additional risk factors, a protective ostomy seems prudent. This approach is endorsed by the current ECCO-ESCP guidelines [28] and other large-volume centers [48]. Finally, prophylaxis against thromboembolism should be provided and continued beyond the discharge from hospital of highrisk patients.

\section{Disclosure Statement}

W.R. received speaker's fees from AbbVie, Falk, Janssen, and Takeda.

\section{Author Contributions}

W.R. and P.K. took the lead in writing the manuscript. All authors provided critical feedback and helped shape the analysis and manuscript. 
1 Burr NE, Lord R, Hull MA, Subramanian V. Decreasing Risk of First and Subsequent Surgeries in Patients with Crohn's Disease in England from 1994 through 2013. Clin Gastroenterol Hepatol. 2019 Sep;17(10):20422049.e4.

2 Candido FD, Fiorino G, Spadaccini M, Danese S, Spinelli A. Are Surgical Rates Decreasing in the Biological Era in IBD? Curr Drug Targets. 2019;20(13):1356-62.

3 Ma C, Moran GW, Benchimol EI, Targownik LE, Heitman SJ, Hubbard JN, et al. Surgical Rates for Crohn's Disease Are Decreasing: A Population-Based Time Trend Analysis and Validation Study. Am J Gastroenterol. 2017 Dec;112(12):1840-8

4 Frolkis AD, Lipton DS, Fiest KM, Negrón ME, Dykeman J, deBruyn J, et al. Cumulative incidence of second intestinal resection in Crohn's disease: a systematic review and meta-analysis of population-based studies. Am J Gastroenterol. 2014 Nov;109(11):1739-48.

5 de Groof EJ, Stevens TW, Eshuis EJ, Gardenbroek TJ, Bosmans JE, van Dongen JM, et al; LIR!C Study Group. Cost-effectiveness of laparoscopic ileocaecal resection versus infliximab treatment of terminal ileitis in Crohn's disease: the LIR!C Trial. Gut. 2019 Oct;68(10): 1774-80.

6 Fumery M, Xiaocang C, Dauchet L, GowerRousseau C, Peyrin-Biroulet L, Colombel JF. Thromboembolic events and cardiovascular mortality in inflammatory bowel diseases: a meta-analysis of observational studies. J Crohn's Colitis. 2014 Jun;8(6):469-79.

7 Kuy S, Dua A, Chappidi R, Seabrook G, Brown KR, Lewis B, et al. The increasing incidence of thromboembolic events among hospitalized patients with inflammatory bowel disease. Vascular. 2015 Jun;23(3):260-4.

8 Wallaert JB, De Martino RR, Marsicovetere PS, Goodney PP, Finlayson SR, Murray JJ, et al. Venous thromboembolism after surgery for inflammatory bowel disease: are there modifiable risk factors? Data from ACS NSQIP. Dis Colon Rectum. 2012 Nov;55(11): 1138-44.

9 Chu TP, Grainge MJ, Card TR. The risk of venous thromboembolism during and after hospitalisation in patients with inflammatory bowel disease activity. Aliment Pharmacol Ther. 2018 Nov;48(10):1099-108.

10 Brady MT, Patts GJ, Rosen A, Kasotakis G, Siracuse JJ, Sachs T, et al. Postoperative Venous Thromboembolism in Patients Undergoing Abdominal Surgery for IBD: A Common but Rarely Addressed Problem. Dis Colon Rectum. 2017 Jan;60(1):61-7.

11 Van Assche G, Dignass A, Bokemeyer B, Danese S, Gionchetti P, Moser G, et al. Second European evidence-based consensus on the diagnosis and management of ulcerative colitis part 3: special situations. J Crohns Colitis. 2013;7:1-33.

12 Gustafsson UO, Scott MJ, Schwenk W, Demartines N, Roulin D, Francis N, et al.; Enhanced Recovery After Surgery (ERAS) Society, for Perioperative Care; European Society for Clinical Nutrition and Metabolism (ESPEN); International Association for Surgical
Metabolism and Nutrition (IASMEN). Guidelines for perioperative care in elective colonic surgery: Enhanced Recovery After Surgery (ERAS $\left({ }^{\circledR}\right)$ ) Society recommendations. World J Surg. 2013 Feb;37(2):259-84.

13 Gillis C, Buhler K, Bresee L, Carli F, Gramlich L, Culos-Reed N, et al. Effects of Nutritional Prehabilitation, With and Without Exercise, on Outcomes of Patients Who Undergo Colorectal Surgery: A Systematic Review and Meta-analysis. Gastroenterology. 2018 Aug; 155(2):391-410.e4.

14 van Rooijen S, Carli F, Dalton S, Thomas G, Bojesen R, Le Guen M, et al. Multimodal prehabilitation in colorectal cancer patients to improve functional capacity and reduce postoperative complications: the first international randomized controlled trial for multimodal prehabilitation. BMC Cancer. BioMed Central. 2019 Jan;19(1):98-11.

15 Grass F, Pache B, Martin D, Hahnloser D, Demartines N, Hübner M. Preoperative Nutritional Conditioning of Crohn's Patients Systematic Review of Current Evidence and Practice. Nutrients. 2017 Jun;9(6):E562.

16 Ayoub F, Kamel AY, Ouni A, Chaudhry N, Ader Y, Tan S, et al. Pre-operative total parenteral nutrition improves post-operative outcomes in a subset of Crohn's disease patients undergoing major abdominal surgery. Gastroenterol Rep (Oxf). 2019 Apr;7(2):10714.

17 Heerasing N, Thompson B, Hendy P, Heap GA, Walker G, Bethune R, et al. Exclusive enteral nutrition provides an effective bridge to safer interval elective surgery for adults with Crohn's disease. Aliment Pharmacol Ther. 2017 Mar;45(5):660-9.

18 Wang H, Zuo L, Zhao J, Dong J, Li Y, Gu L, et al. Impact of Preoperative Exclusive Enteral Nutrition on Postoperative Complications and Recurrence After Bowel Resection in Patients with Active Crohn's Disease. World J Surg. 2016 Aug;40(8):1993-2000.

19 Li G, Ren J, Wang G, Hu D, Gu G, Liu S, et al. Preoperative exclusive enteral nutrition reduces the postoperative septic complications of fistulizing Crohn's disease. Eur J Clin Nutr. 2014 Apr;68(4):441-6.

20 Jacobson S. Early postoperative complications in patients with Crohn's disease given and not given preoperative total parenteral nutrition. Scand J Gastroenterol. 2012 Feb; 47(2):170-7.

21 Miller T, Suskind DL. Exclusive enteral nutrition in pediatric inflammatory bowel disease. Curr Opin Pediatr. 2018 Oct;30(5):671-6.

22 MacLellan A, Moore-Connors J, Grant S, Cahill L, Langille MGI, Van Limbergen J. The Impact of Exclusive Enteral Nutrition (EEN) on the Gut Microbiome in Crohn's Disease: A Review. Nutrients. 2017 May 1;9(5):E0447.

23 Svolos V, Hansen R, Nichols B, Quince C, Ijaz UZ, Papadopoulou RT, et al. Treatment of Active Crohn's Disease with an Ordinary Food-Based Diet that Replicates Exclusive Enteral Nutrition. Gastroenterology. 2019 Apr;156(5):1354-1367.e6.

24 Weimann A, Braga M, Carli F, Higashiguchi T, Hübner M, Klek S, et al. ESPEN guideline:
Clinical nutrition in surgery. Clin Nutr. 2017; 36:623-50.

25 Braga M, Ljungqvist O, Soeters P, Fearon K, Weimann A, Bozzetti F, et al. ESPEN Guidelines on Parenteral Nutrition: surgery. Clin Nutr. 2009;28:378-86.

26 Abou Khalil M, Abou-Khalil J, Motter J, Vasilevsky CA, Morin N, Ghitulescu G, et al. Immunosuppressed Patients with Crohn's Disease Are at Increased Risk of Postoperative Complications: results from the ACS-NSQIP Database. J Gastrointest Surg. 2019 Jun;23(6): 1188-97.

27 Nguyen GC, Elnahas A, Jackson TD. The impact of preoperative steroid use on short-term outcomes following surgery for inflammatory bowel disease. J Crohns Colitis. 2014 Dec; 8(12):1661-7.

28 Bemelman WA, Warusavitarne J, Sampietro GM, Serclova Z, Zmora O, Luglio G, et al. ECCO-ESCP Consensus on Surgery for Crohn's Disease. J Crohns Colitis. 2018;12:1-16.

29 Thalayasingam N, Isaacs JD. Anti-TNF therapy. Best Pract Res Clin Rheumatol. 2011 Aug;25(4):549-67.

30 Myrelid P, Martí-Gallostra M, Ashraf S, Sunde ML, Tholin M, Oresland T, et al. Complications in surgery for Crohn's disease after preoperative antitumour necrosis factor therapy. Br J Surg. 2014 Apr;101(5):539-45.

31 Yamamoto T, Spinelli A, Suzuki Y, SaadHossne R, Teixeira FV, de Albuquerque IC, et al. Risk factors for complications after ileocolonic resection for Crohn's disease with a major focus on the impact of preoperative immunosuppressive and biologic therapy: A retrospective international multicentre study. United European Gastroenterol J. 2016 Dec; 4(6):784-93.

32 Kotze PG, Saab MP, Saab B, da Silva Kotze LM, Olandoski M, Pinheiro LV, et al. Tumor Necrosis Factor Alpha Inhibitors Did Not Influence Postoperative Morbidity after Elective Surgical Resections in Crohn's Disease. Dig Dis Sci. 2017 Feb;62(2):456-64.

33 Brouquet A, Maggiori L, Zerbib P, Lefevre JH, Denost Q, Germain A, et al.; GETAID chirurgie group. Anti-TNF Therapy Is Associated with an Increased Risk of Postoperative Morbidity after Surgery for Ileocolonic Crohn Disease: Results of a Prospective Nationwide Cohort. Ann Surg. 2018 Feb;267(2):221-8.

34 Fumery M, Seksik P, Auzolle C, Munoz-Bongrand N, Gornet JM, Boschetti G, et al.; REMIND Study Group Investigators. Postoperative Complications after Ileocecal Resection in Crohn's Disease: A Prospective Study from the REMIND Group. Am J Gastroenterol. 2017 Feb;112(2):337-45.

35 Lau C, Dubinsky M, Melmed G, Vasiliauskas E, Berel D, McGovern D, et al. The impact of preoperative serum anti-TNFa therapy levels on early postoperative outcomes in inflammatory bowel disease surgery. Ann Surg. 2015 Mar;261(3):487-96.

36 Colombel JF, Sands BE, Rutgeerts P, Sandborn W, Danese S, D'Haens G, et al. The safety of vedolizumab for ulcerative colitis and Crohn's disease. Gut. 2017 May;66(5):83951. 
37 Yung DE, Horesh N, Lightner AL, Ben-Horin S, Eliakim R, Koulaouzidis A, et al. Systematic Review and Meta-analysis: Vedolizumab and Postoperative Complications in Inflammatory Bowel Disease. Inflamm Bowel Dis. 2018 Oct;24(11):2327-38.

38 Lightner AL, Edward V Loftus Jr, McKenna NP, Raffals LE. Vedolizumab in the perioperative management of inflammatory bowel disease. Curr Drug Targets. 2019;20(13): 1317-22.

39 Yamada A, Komaki Y, Patel N, Komaki F, Aelvoet AS, Tran AL, et al. Risk of Postoperative Complications among Inflammatory Bowel Disease Patients Treated Preoperatively with Vedolizumab. Am J Gastroenterol. 2017 Sep;112(9):1423-9.

40 Law CC, Narula A, Lightner AL, McKenna NP, Colombel JF, Narula N. Systematic Review and Meta-Analysis: Preoperative Vedolizumab Treatment and Postoperative Complications in Patients with Inflammatory Bowel Disease. J Crohn's Colitis. 2018 Apr; 12(5):538-45
41 Novello M, Stocchi L, Steele SR, Holubar SD, Duraes LC, Kessler H, et al. Case-matched comparison of postoperative outcomes following surgery for inflammatory bowel disease after exposure to vedolizumab vs. other biologics. J Crohn's Colitis. 2019 Jul;jjz129.

42 Shim HH, Ma C, Kotze PG, Seow CH, Al-Farhan $\mathrm{H}, \mathrm{Al}$-Darmaki AK, et al. Preoperative Ustekinumab Treatment Is Not Associated with Increased Postoperative Complications in Crohn's Disease: A Canadian Multi-Centre Observational Cohort Study. J Can Assoc Gastroenterol. 2018 Sep;1(3):115-23.

43 Lightner AL, McKenna NP, Tse CS, Hyman N, Smith R, Ovsepyan G, et al. Postoperative Outcomes in Ustekinumab-Treated Patients Undergoing Abdominal Operations for Crohn's Disease. J Crohn's Colitis. 2018 Mar; 12(4):402-7.

44 Balentine CJ, Naik AD, Robinson CN, Petersen NJ, Chen GJ, Berger DH, et al. Association of high-volume hospitals with greater likelihood of discharge to home following colorectal surgery. JAMA Surg. 2014 Mar;149(3): 244-51.
45 Ananthakrishnan AN, McGinley EL, Binion DG. Does it matter where you are hospitalized for inflammatory bowel disease? A nationwide analysis of hospital volume. Am J Gastroenterol. 2008 Nov;103(11):2789-98.

46 Nguyen GC, Steinhart AH. The impact of surgeon volume on postoperative outcomes after surgery for Crohn's disease. Inflamm Bowel Dis. 2014 Feb;20(2):301-6.

47 Galata C, Kienle P, Weiss C, Seyfried S, Reißfelder C, Hardt J. Risk factors for early postoperative complications in patients with Crohn's disease after colorectal surgery other than ileocecal resection or right hemicolectomy. Int J Colorectal Dis. 2019 Feb;34(2): 293-300.

48 Lightner AL, Shen B. Perioperative use of immunosuppressive medications in patients with Crohn's disease in the new "biological era”. Gastroenterol Rep (Oxf). 2017 Aug;5(3): 165-77. 